\title{
BIBECHANA
}

A Multidisciplinary Journal of Science, Technology and Mathematics ISSN 2091-0762 (Print), 2382-5340 (0nline)

Journal homepage: http://nepjol.info/index.php/BIBECHANA

Publisher: Research Council of Science and Technology, Biratnagar, Nepal

\section{NBO, chemical reactivity, thermodynamic properties and hyperpolarizability analysis of aristolochic acid II}

\author{
Bhawani Datt Joshi \\ Department of Physics, Tribhuvan University, Siddhanath Sc. Campus, Mahendranagar, Nepal \\ *Email bdjoshi_007@yahoo.com, pbdjoshi@gmail.com \\ Article history: Received 3 September, 2016; Accepted 8 October, 2016 \\ DOI: http://dx.doi.org/10.3126/bibechana.v14i0.15892 \\ This work is licensed under the Creative Commons CC BY-NC License. \\ https://creativecommons.org/licenses/by-nc/4.0/ \\ (c) (1) (8)
}

Abstract

Alkaloids are a group of naturally occurring chemical compounds and show immense potential of medicinal uses in traditional systems. In this work, a computational study on an alkaloid aristolochc acidid II (AA II) is presented using density functional theory, B3LYP functional employing 6-311G (d,p) basis set. Natural bond orbital analysis has been carried out to investigate the various conjugative and hyperconjugative interactions within the molecule and their second-order stabilisation energy $\left(\mathrm{E}^{(2)}\right)$. The local nucleophilic reactivity descriptors such as Fukui functions $\left(f_{k}^{+}, f_{k}^{-}\right)$, local softness $\left(s_{k}^{+}, s_{k}^{-}\right)$and electrophilicity indices $\left(\omega_{k}^{+}, \omega_{k}^{-}\right)$analyses have been carried out to determine the reactive sites within the molecule. The non-linear optical properties have been calculated using the same basis set. The calculated value of the first order hyperpolarisability $\left(\beta_{0}\right)$, suggests that the investigated molecule is an attractive object in future for non-linear optical properties.

Keywords: AA II; DFT; NBO; chemical reactivity; hyperpolarizability.

\section{Introduction}

Majority of drugs in use today are natural products, natural product mimics or semi synthetic derivatives. Therefore in recent times, focus on plant research has increased all over the world and large body of evidence has been collected to show immense potential of medicinal plants used in various traditional systems. Plants are sources of natural antioxidants, and some of the compounds have significant antioxidative properties and health benefits. Aristolochic acids (AAs) which mainly include aristolochic acid I (AA I), aristolochic acid II (AA II) and aristolochic acid III (AA III) are normally present in Aristolochia and Asarum of Aristolochiaceae [1]. In oriental medicine the fruit of Aristolochia is given for cough and dyspnea. Their roots have biological functions including treatment of stomach-ache, 
toothache, eczema, hypertension relief, rheumatism relief, leukocyte enhancement, edema therapy, poisonous snake bites as well as analgesic and diuretic effects [2,3]. In the family of natural products, the alkaloids occupy a unique place and provide challenging problems for structural elucidation, synthetic and biosynthetic studies. Because of their very complex structure and unique places the determination of their constitution and the discovery of the methods producing them synthetically offer attractive problems to the chemist and though a great deal has been accomplished much still remains to be done in this field. Vibrational spectroscopy is a very valuable method for studying the dynamical behavior and to gain insight into the electronic structures of alkaloids at microscopic level [4]. However, both the Raman and IR are the best traditional methods for the vibrational analysis and particularly for the non-destructive characterization of the substances [5], but in the recent years there has been interest in the application of $a b$ initio calculations to the alkaloids as it provide the additional vibrational spectroscopic data [3-6].

In the present work the chemical reactivity descriptors, thermodynamic properties and the natural bond orbitals (NBOs) analysis of an alkaloid aristolochic acid II have been communicated. The aim of this study was to determine the stabilization energy when the system acquires an additional charge from the environment and the direction of the charge transfer. Similarly, the variation of the thermodynamic properties with the temperature and, hybridization, conjugation and charge transfer in the polyatomic wave functions theoretically using ab initio HF and density functional theory (DFT) [7]. We had presented some spectroscopic analysis on the title molecule in our previous work [8]. The crystal structure and optimized structure of AA II are as shown in the Figure 1a and b.

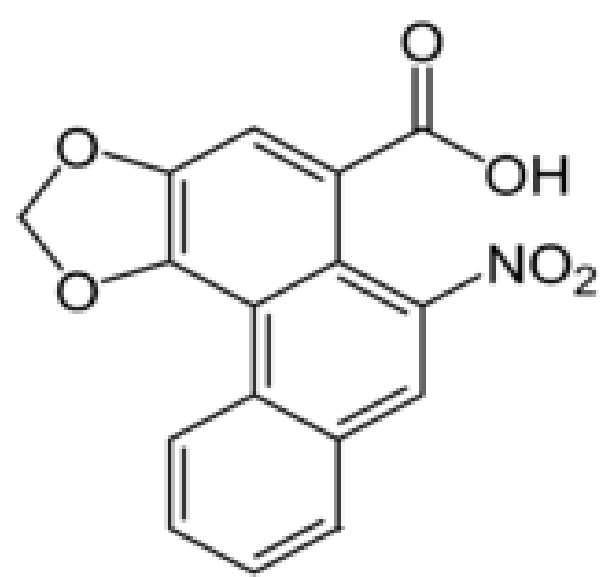

Fig. 1(a): Crystal structure of AA II.

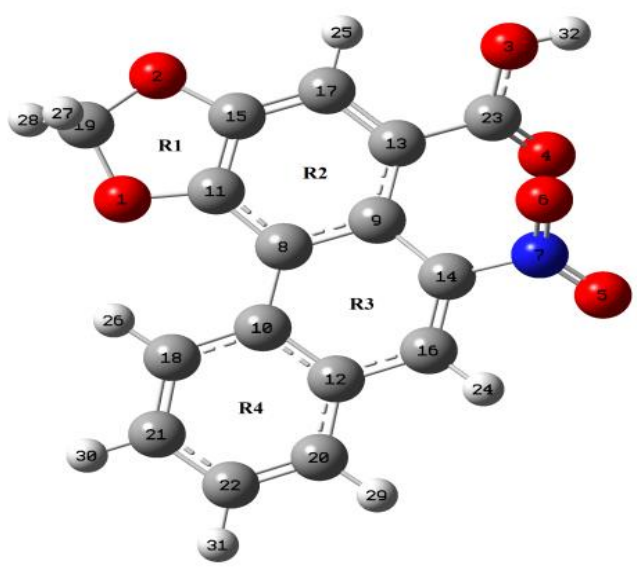

Fig. 1(b): Optimized structure of AA II.

\section{Materials and Methods}

\subsection{Computational Details}

Geometry optimization has been performed as the first task of the computational work. The geometric parameters available from the PubChem data base [9] have been used as the basis for the optimization. These optimized parameters were computed by ab intio HF and the DFT using Gaussian 09 [10] program package employing B3LYP/6-311G (d,p) basis set. The DFT calculations were mainly carried out in the 
frame-work of the Becke-Lee-Yang-Parr [B3LYP] functional, in which the exchange functional is a local spin density exchange with Becke gradient correction [11] and the correlation functional is that of Lee, Yang and Parr with both local and nonlocal terms [12,13].

\section{Results and Discussion}

\subsection{Natural bond Orbital (NBO) Analysis}

NBO analysis is one of the efficient methods for studying hybridization, conjugative interactions, covalence effects and charge transfer in polyatomic wave functions [4]. In the present work, utilizing the second-order micro-disturbance theory analysis, we have reported some of the electron donor orbital, acceptor orbital and the interacting stabilization energy. Higher the value of stabilization energy $\mathrm{E}^{(2)}$ more is the intensity of the interaction between electron donors and electron acceptors, i.e. the more donating tendency from electron donors to electron acceptors. The hyperconjugative interaction energy was deduced from the second-order perturbation approach [14-16].

$$
E^{(2)}=-\frac{n_{\sigma}\langle\sigma|F| \sigma\rangle^{2}}{E_{\sigma *}-E_{\sigma}}=-n_{\sigma}\left|\frac{F_{i j}^{2}}{\Delta E}\right|
$$

where $\langle\sigma|F| \sigma\rangle^{2}$, or $F_{i j}^{2}$ is the Fock matrix element between $\mathrm{i}$ and $\mathrm{j} \mathrm{NBO}$ orbital, $E_{\sigma}$ and $E_{\sigma *}$ are the energies of $\sigma$ and $\sigma^{*}$ NBO's, and $n_{\sigma}$ is the population of the donor orbital. The larger the $\mathrm{E}^{(2)}$ value the more intensive is interaction, the greater the extent of conjugation of the whole system [16]. Hyperconjugation may be given as a stabilizing effect that arises from overlap between an occupied orbital with another neighboring electron deficient orbital when these orbitals are properly oriented. The most important interaction between "filled" (donor) Lewis type NBOs and "empty" (acceptor) nonLewis NBOs are reported in Table 1.

There occurs a strong intramolecular hyperconjugative interactions of $\pi$ electrons of the rings R2 and R3 from $\mathrm{C} 11-\mathrm{C} 15, \mathrm{C} 13-\mathrm{C} 17, \mathrm{C} 10-\mathrm{C} 12$ and $\mathrm{C} 14-\mathrm{C} 16$ to the $\pi^{*}(\mathrm{C} 8-\mathrm{C} 9)$ bond of which increases the electron density $0.474 \mathrm{e}$ leading to the stabilization. This enhanced the further conjugation of the $\pi^{*}(\mathrm{C} 8$ C9) NBO mainly with $\pi^{*}(\mathrm{C} 10-\mathrm{C} 12)$ and $\pi^{*}(\mathrm{C} 14-\mathrm{C} 16)$ resulting to the high stabilization of 236.16 and $134.76 \mathrm{kcal} / \mathrm{mol}$, respectively. Also, there occur some another hypercinjugative interactions of $\pi$ electrons from $\mathrm{C} 13-\mathrm{C} 17 \rightarrow \pi^{*}(\mathrm{C} 11-\mathrm{C} 15)$ with ED $0.40135 \mathrm{e}, \mathrm{C} 14-\mathrm{C} 16 \rightarrow \pi^{*}(\mathrm{O} 5-\mathrm{N} 7)$ with $\mathrm{ED}$ 0.60349 e, $\mathrm{C} 18-\mathrm{C} 21 \rightarrow \pi^{*}(\mathrm{C} 10-\mathrm{C} 12)$ with ED $0.44633 \mathrm{e}$ and $\mathrm{C} 20-\mathrm{C} 22 \rightarrow \pi^{*}(\mathrm{C} 18-\mathrm{C} 21)$ with ED $0.27488 \mathrm{e}$ leading to the stabilization energies $21.06,16.48,18.62$ and $18.77 \mathrm{kcal} / \mathrm{mol}$, respectively. Similarly, the enhanced NBOs $\pi^{*}(\mathrm{C} 11-\mathrm{C} 15)$ conjugate with $\pi^{*}(\mathrm{C} 13-\mathrm{C} 17)$ in ring R2 which further conjugates with $\pi^{*}(\mathrm{O} 4-\mathrm{C} 23)$ of the carboxyl group leading to the corresponding stabilization energies 276.35 and $112.33 \mathrm{kcal} / \mathrm{mol}$, respectively. The electron donation related to the resonance in the molecule is from $\mathrm{LP}(2) \mathrm{O} 3$ to antibonding acceptor $\pi^{*}(\mathrm{O} 4-\mathrm{C} 23)$ of carboxyl group $(41.00 \mathrm{kcal} / \mathrm{mol})$ and from $\mathrm{LP}(2) \mathrm{O} 6$ to $\pi^{*}(\mathrm{O} 5-\mathrm{N} 7)$ of $\mathrm{NO}_{2}$ group $(168.74 \mathrm{kcal} / \mathrm{mol})$. The interactions are mainly confined between the rings and the lone pair electron groups. These charge transfer in the system lead to the structure activity of the molecule. A comparison of the NBO and Mullikan charges is given in the Table 2 . 
Bhawani Dutt Joshi / BIBECHANA 14 (2017) 86-97 : RCOST p.89 (Online Publication: Dec., 2016)

Table 1: Second order perturbation theory analysis of Fock matrix in NBO basis for AA II.

\begin{tabular}{|c|c|c|c|c|c|c|}
\hline Donor NBIO(i) & $\mathrm{ED}(\mathrm{i}) / \mathrm{e}$ & Acceptor NBO(j) & $\mathrm{ED}(\mathrm{j}) / \mathrm{e}$ & $\begin{array}{l}\mathrm{E}(2)^{\mathrm{a}} \\
(\mathrm{kcl} / \mathrm{mol})\end{array}$ & {$[E(j)-E(i)]^{b}$} & $F(i, j)^{c}$ \\
\hline $\mathrm{LP}(2) \mathrm{O} 1$ & 1.85366 & $\pi^{*}(\mathrm{C} 11-\mathrm{C} 15)$ & 0.40135 & 23.22 & 0.35 & 0.087 \\
\hline $\mathrm{LP}(2) \mathrm{O} 2$ & 1.85651 & $\pi^{*}(\mathrm{C} 11-\mathrm{C} 15)$ & 0.40135 & 23.59 & 0.35 & 0.086 \\
\hline $\mathrm{LP}(2) \mathrm{O} 3$ & 1.82127 & $\pi^{*}(\mathrm{O} 4-\mathrm{C} 23)$ & 0.24140 & 41.00 & 0.36 & 0.111 \\
\hline \multirow[t]{2}{*}{$\mathrm{LP}(2) \mathrm{O} 4$} & 1.83912 & $\sigma^{*}(\mathrm{O} 3-\mathrm{C} 23)$ & 0.09844 & 32.38 & 0.61 & 0.128 \\
\hline & & $\sigma^{*}(\mathrm{C} 13-\mathrm{C} 23)$ & 0.06750 & 18.44 & 0.68 & 0.102 \\
\hline \multirow[t]{2}{*}{$\mathrm{LP}(2) \mathrm{O} 5$} & 1.89423 & $\sigma^{*}(\mathrm{O} 6-\mathrm{N} 7)$ & 0.07135 & 19.19 & 0.71 & 0.105 \\
\hline & & $\sigma^{*}(\mathrm{~N} 7-\mathrm{C} 14)$ & 0.10978 & 14.26 & 0.55 & 0.079 \\
\hline \multirow[t]{2}{*}{$\mathrm{LP}(2) \mathrm{O} 6$} & 1.89355 & $\sigma^{*}(\mathrm{O} 6-\mathrm{N} 7)$ & 0.07135 & 18.60 & 0.73 & 0.105 \\
\hline & & $\pi^{*}(\mathrm{O} 5-\mathrm{N} 7)$ & 0.60349 & 168.74 & 0.15 & 0.144 \\
\hline$\sigma(\mathrm{C} 11-\mathrm{C} 15)$ & 1.97681 & $\sigma^{*}(\mathrm{C} 8-\mathrm{C} 11)$ & 0.02801 & 6.07 & 1.27 & 0.079 \\
\hline$\sigma(\mathrm{C} 14-\mathrm{C} 16)$ & 1.97140 & $\sigma^{*}(\mathrm{C} 9-\mathrm{C} 14)$ & 0.03163 & 5.49 & 1.24 & 0.074 \\
\hline$\sigma(\mathrm{C} 16-\mathrm{H} 24)$ & 1.97338 & $\sigma^{*}(\mathrm{C} 9-\mathrm{C} 14)$ & 0.03163 & 6.26 & 1.02 & 0.072 \\
\hline$\pi(\mathrm{C} 8-\mathrm{C} 9)$ & 1.58253 & $\sigma^{*}(\mathrm{O} 1-\mathrm{C} 11)$ & 0.02832 & 6.00 & 0.99 & 0.069 \\
\hline \multirow[t]{4}{*}{$\pi(\mathrm{C} 10-\mathrm{C} 12)$} & 1.56437 & $\pi^{*}(\mathrm{C} 8-\mathrm{C} 9)$ & 0.47400 & 16.91 & 0.26 & 0.060 \\
\hline & & $\pi^{*}(\mathrm{C} 14-\mathrm{C} 16)$ & 0.22748 & 16.78 & 0.28 & 0.065 \\
\hline & & $\pi^{*}(\mathrm{C} 18-\mathrm{C} 21)$ & 0.27488 & 17.31 & 0.28 & 0.065 \\
\hline & & $\pi^{*}(\mathrm{C} 20-\mathrm{C} 22)$ & 0.27301 & 17.26 & 0.28 & 0.065 \\
\hline \multirow[t]{2}{*}{$\pi(\mathrm{C} 11-\mathrm{C} 15)$} & 1.63802 & $\pi^{*}(\mathrm{C} 8-\mathrm{C} 9)$ & 0.47400 & 17.68 & 0.30 & 0.067 \\
\hline & & $\pi^{*}(\mathrm{C} 13-\mathrm{C} 17)$ & 0.36737 & 20.25 & 0.31 & 0.071 \\
\hline \multirow[t]{3}{*}{$\pi(\mathrm{C} 13-\mathrm{C} 17)$} & 1.68334 & $\pi^{*}(\mathrm{O} 4-\mathrm{C} 23)$ & 0.24140 & 17.24 & 0.30 & 0.065 \\
\hline & & $\pi^{*}(\mathrm{C} 8-\mathrm{C} 9)$ & 0.47400 & 18.48 & 0.28 & 0.067 \\
\hline & & $\pi^{*}(\mathrm{C} 11-\mathrm{C} 15)$ & 0.40135 & 21.06 & 0.27 & 0.069 \\
\hline \multirow[t]{3}{*}{$\pi(\mathrm{C} 14-\mathrm{C} 16)$} & 1.77190 & $\pi^{*}(\mathrm{O} 5-\mathrm{N} 7)$ & 0.60349 & 16.48 & 0.17 & 0.052 \\
\hline & & $\pi^{*}(\mathrm{C} 8-\mathrm{C} 9)$ & 0.47400 & 13.55 & 0.30 & 0.061 \\
\hline & & $\pi^{*}(\mathrm{C} 10-\mathrm{C} 12)$ & 0.44633 & 12.99 & 0.31 & 0.060 \\
\hline \multirow[t]{2}{*}{$\pi(\mathrm{C} 18-\mathrm{C} 21)$} & 1.68756 & $\pi^{*}(\mathrm{C} 10-\mathrm{C} 12)$ & 0.44633 & 18.62 & 0.28 & 0.067 \\
\hline & & $\pi^{*}(\mathrm{C} 20-\mathrm{C} 22)$ & 0.27301 & 18.46 & 0.29 & 0.066 \\
\hline \multirow[t]{2}{*}{$\pi(\mathrm{C} 20-\mathrm{C} 22)$} & 1.69812 & $\pi^{*}(\mathrm{C} 10-\mathrm{C} 12)$ & 0.44633 & 18.47 & 0.29 & 0.067 \\
\hline & & $\pi^{*}(\mathrm{C} 18-\mathrm{C} 21)$ & 0.27488 & 18.77 & 0.29 & 0.067 \\
\hline \multirow[t]{5}{*}{$\pi^{*}(\mathrm{C} 8-\mathrm{C} 9)$} & 0.47400 & $\pi^{*}(\mathrm{C} 10-\mathrm{C} 12)$ & 0.44633 & 16.36 & 0.28 & 0.061 \\
\hline & & $\pi^{*}(\mathrm{C} 11-\mathrm{C} 15)$ & 0.40135 & 23.40 & 0.26 & 0.070 \\
\hline & & $\pi^{*}(\mathrm{C} 13-\mathrm{C} 17)$ & 0.36737 & 18.20 & 0.28 & 0.064 \\
\hline & & $\pi^{*}(\mathrm{C} 10-\mathrm{C} 12)$ & 0.44633 & 236.16 & 0.01 & 0.074 \\
\hline & & $\pi^{*}(\mathrm{C} 14-\mathrm{C} 16)$ & 0.22748 & 134.76 & 0.02 & 0.072 \\
\hline$\pi^{*}(\mathrm{C} 11-\mathrm{C} 15)$ & 0.40135 & $\pi^{*}(\mathrm{C} 13-\mathrm{C} 17)$ & 0.36737 & 276.35 & 0.01 & 0.084 \\
\hline$\pi^{*}(\mathrm{C} 13-\mathrm{C} 17)$ & 0.36737 & $\pi^{*}(\mathrm{O} 4-\mathrm{C} 23)$ & 0.24140 & 112.33 & 0.01 & 0.063 \\
\hline
\end{tabular}

${ }^{a} E^{(2)}$ means energy of hyper conjugative interaction (stabilization energy).

${ }^{b}$ Energy difference between donor (i) and acceptor ( j) NBO orbitals.

${ }^{c} \mathrm{~F}(\mathrm{i}, \mathrm{j})$ is the Fock matrix element between $\mathrm{i}$ and $\mathrm{j}$ NBO orbitals. 
Table 2: Comparison between NBO and Mullikan charges (esu) of AA II.

\begin{tabular}{rrcccc}
\hline Atom No & NBO charges & Mulliken charges & Atom No & NBO charges & $\begin{array}{l}\text { Mulliken } \\
\text { charges }\end{array}$ \\
\hline 1 O & -0.541 & -0.364 & & & \\
2 O & -0.523 & -0.339 & $14 \mathrm{C}$ & 0.108 & 0.067 \\
3 O & -0.688 & -0.064 & $15 \mathrm{C}$ & 0.269 & 0.189 \\
4 O & -0.595 & -0.333 & $16 \mathrm{C}$ & -0.147 & 0.172 \\
$5 \mathrm{O}$ & -0.367 & -0.245 & $17 \mathrm{C}$ & -0.201 & 0.122 \\
$6 \mathrm{O}$ & -0.384 & -0.271 & $18 \mathrm{C}$ & -0.180 & 0.080 \\
$7 \mathrm{~N}$ & 0.522 & 0.156 & $19 \mathrm{C}$ & 0.318 & 0.429 \\
$8 \mathrm{C}$ & -0.061 & -0.045 & $20 \mathrm{C}$ & -0.165 & 0.032 \\
$9 \mathrm{C}$ & -0.032 & 0.103 & $21 \mathrm{C}$ & -0.179 & 0.014 \\
$10 \mathrm{C}$ & -0.026 & 0.016 & $22 \mathrm{C}$ & -0.189 & 0.027 \\
$11 \mathrm{C}$ & 0.298 & 0.078 & $23 \mathrm{C}$ & 0.820 & 0.328 \\
$12 \mathrm{C}$ & -0.054 & -0.084 & & & \\
\hline
\end{tabular}

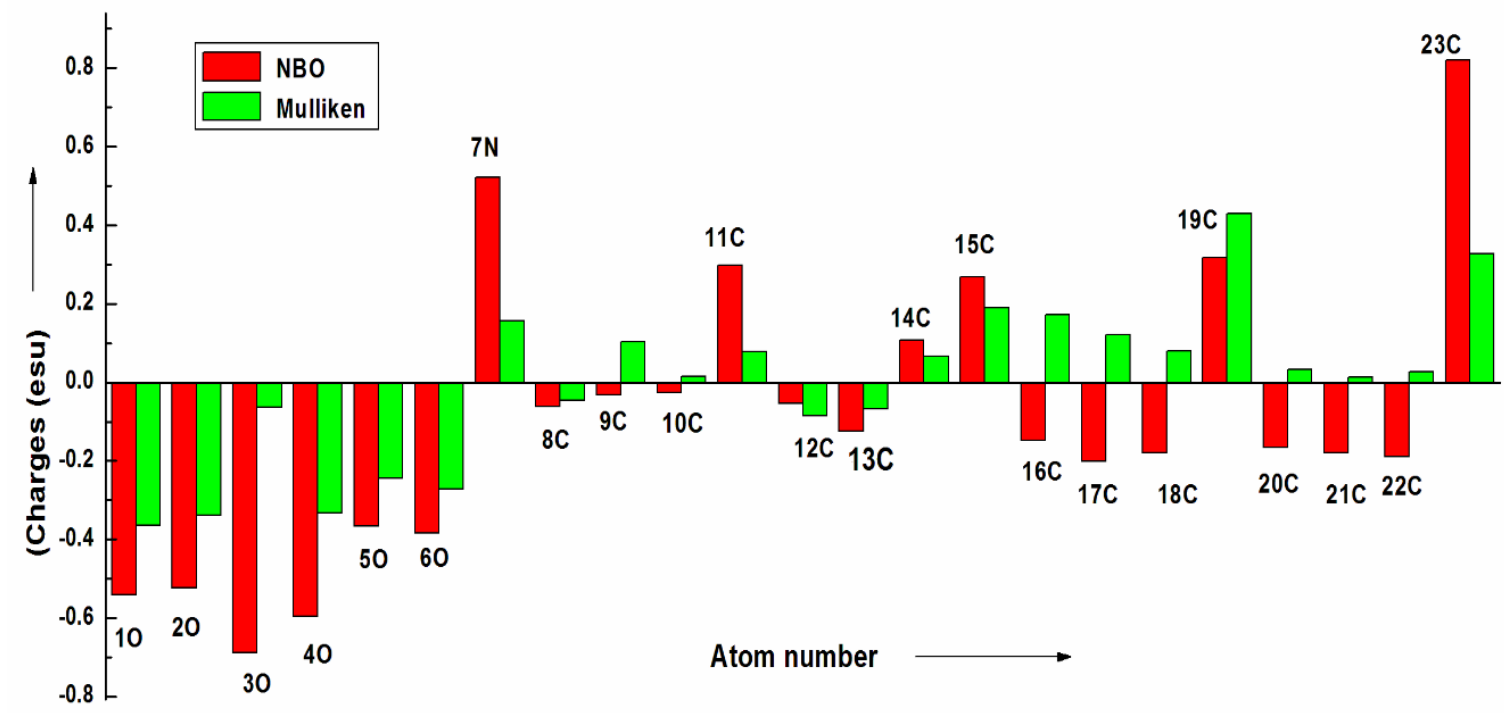

Fig. 2: Correlation between NBO and Mulliken charges.

\subsection{Chemical Reactivity}

\section{2 (a) Global Reactivity Descriptors}

Electrophilicity and hardness are two important molecular properties, which are useful for interpreting and understanding the stability and reactivity of molecular system [17]. According to the Hohenberg and Kohn (HK), theorems [7], the energy of the basic state of an electronic system is a functional of electron density. On the basis of Koopman's theorem [17], global reactivity descriptors: electronegativity $(\chi)$, 
chemical potential $(\mu)$, global hardness $(\eta)$, global softness $(S)$ and global electrophilicity index $(\omega)$ were calculated using the energies of frontier molecular orbitals $\mathrm{E}_{\text {номо }}, \mathrm{E}_{\mathrm{LUMO}}$ and given by relations (1) - (5) [18-20].

$\chi=-\frac{1}{2}\left[E_{\text {Номо }}+E_{\text {LUMO }}\right]$

$\mu=-\chi=\frac{1}{2}\left[E_{\text {номо }}+E_{\text {LUMO }}\right]$

$\eta=\frac{1}{2}\left[E_{\text {LUMO }}-E_{\text {HOMO }}\right]$

$\mathrm{S}=\frac{1}{2} \eta$

$\omega=\frac{\mu^{2}}{2 \eta}$

$\Delta N_{\max }=-\frac{\mu}{\eta}$

According to Parr et al., electrophilicity index $(\omega)$, a positive and finite quantity, is a global reactivity index similar to the chemical hardness (a measure of the resistance of a system to transfer charge), and chemical potential. This new reactivity index measures the stabilization in energy when the system acquires an additional electronic charge $(\Delta \mathrm{N})$ from the environment up to saturation. The direction of the charge transfer is completely determined by the electronic chemical potential of the molecule because an electrophile is a chemical species capable of accepting electrons from the environments. Therefore its energy must decrease upon accepting electronic charge and its electronic chemical potential must be negative. The energies of frontier energy levels ( $\mathrm{E}_{\text {номо, }} \mathrm{E}_{\mathrm{LUMO}}$ ), energy band gap $(\Delta \mathrm{E})$, electronegativity $(\chi)$ that representing the tendency of atoms or molecules to attract electrons; chemical potential $(\mu)$, global hardness $(\eta)$, global softness $(\mathrm{S})$, global electrophilicity index $(\omega)$, and additional electronic charge $(\Delta \mathrm{N})$ for AA II are listed in the Table 3. The calculated high value of electrofilicity index $(\omega)$ shows that the molecule behaves as a strong electrophile.

Table 3: Calculated $\mathrm{E}_{\text {номо }}$, $\mathrm{E}_{\mathrm{Lumo}}$, energy band gap $(\Delta \mathrm{E})$, electronegativity $(\chi)$, chemical potential $(\mu)$, global hardness $(\eta)$, global softness $(s)$, global electrophilicity index $(\omega)$ and additional electronic charge $(\Delta \mathrm{Nmax})(\mathrm{in} \mathrm{eV})$ for AA II , using B3LYP/6-31G (d,p).

\begin{tabular}{llllllll}
\hline Е $_{\text {Hомо }}$ & $\mathrm{E}_{\text {LUMO }}$ & $\Delta \mathrm{E}$ & $\mu$ & $\eta$ & $\mathrm{S}$ & $\omega$ & $\Delta \mathrm{N}_{\max }$ \\
\hline-6.113904 & -2.396963 & 3.716941 & -4.267835 & 1.858471 & 0.269038 & 4.900378 & 2.296299 \\
\hline
\end{tabular}

\section{2 (b) Local Reactivity Descriptors}

Using Hirshfeld population analysis of neutral, cation and anion state of molecule, Fukui functions $\left(f_{k}^{+}\right.$, $\left.f_{k}^{-}, f_{k}^{0}\right)[20,21]$, are calculated at same calculation method B3LYP/6-31 G (d,p) using following relations (7-9):

$f_{k}^{+}=[\mathrm{q}(\mathrm{N}+1)-\mathrm{q}(\mathrm{N})]$ for nucleophilic attack

$f_{k}^{-}=[\mathrm{q}(\mathrm{N})-\mathrm{q}(\mathrm{N}-1)]$ for electrophilic attack

$f_{k}^{0}=1 / 2[\mathrm{q}(\mathrm{N}+1)-\mathrm{q}(\mathrm{N}-1)]$ for radical attack

where $\mathrm{N}, \mathrm{N}-1$ and $\mathrm{N}+1$ are total electrons present in neutral, cation and anion state of molecule, respectively.

Local softnesses $\left(s_{k}^{+}, s_{k}^{-}, s_{k}^{0}\right)$ and local electrophilicity indices $\left(\omega_{k}^{+}, \omega_{k}^{-}, \omega_{k}^{0}\right)$, also used to describe the reactivity of atoms in molecule, are calculated using the following equations (10) and (11):

$s_{k}^{+}=\mathrm{S} f_{k}^{+}, s_{k}^{-}=\mathrm{S} f_{k}^{-}, s_{k}^{0}=\mathrm{S} f_{k}^{0}$

$\omega_{k}^{+}=\omega f_{k}^{+}, \omega_{k}^{-}=\omega f_{k}^{-}, \omega_{k}^{0}=\omega f_{k}^{0}$

where,,+- 0 signs show nucleophilic, electrophilic and radical attack, respectively. 
Bhawani Dutt Joshi / BIBECHANA 14 (2017) 86-97 : RCOST p.92 (Online Publication: Dec., 2016)

Table 4: Hirshfelf atomic charges (in esu), Fukui functions $\left(f_{k}^{+}, f_{k}^{-}\right)$; Local softness $\left(s_{k}^{+}, s_{k}^{-}\right)$; and local electrophilicity indices $\left(\omega_{k}^{+}, \omega_{k}^{-}\right)$; in $\mathrm{eV}$ for atomic sites of AA II, using Hirshfeld population analysis at B3LYP/6-31G (d,p) level.

\begin{tabular}{|c|c|c|c|c|c|c|c|c|c|}
\hline \multirow[t]{2}{*}{$\begin{array}{l}\text { Atom } \\
\text { no. }\end{array}$} & \multicolumn{3}{|c|}{ Hirshfeld atomic charges } & \multicolumn{2}{|c|}{ Fukui functions } & \multicolumn{2}{|c|}{ Local softness } & \multicolumn{2}{|c|}{$\begin{array}{l}\text { Local } \\
\text { electrophilicity } \\
\text { indices }\end{array}$} \\
\hline & $\mathrm{q}_{\mathrm{N}}$ & $\mathrm{q}_{\mathrm{N}+1}$ & $\mathrm{q}_{\mathrm{N}-1}$ & $f_{k}^{+}$ & $f_{k}^{-}$ & $S_{k}^{+}$ & $s_{k}^{-}$ & $\omega_{k}^{+}$ & $\omega_{k}^{-}$ \\
\hline $1 \mathrm{O}$ & -0.137056 & -0.082403 & -0.154852 & 0.05465 & 0.01779 & 0.0147 & 0.0048 & 0.2678 & 0.0872 \\
\hline $2 \mathrm{O}$ & -0.154125 & -0.084260 & -0.180316 & 0.06986 & 0.02619 & 0.0188 & 0.0070 & 0.3424 & 0.1283 \\
\hline 30 & 0.014549 & 0.054444 & -0.024939 & 0.03989 & 0.03948 & 0.0107 & 0.0106 & 0.1955 & 0.1935 \\
\hline $4 \mathrm{O}$ & -0.285351 & -0.247806 & -0.310391 & 0.03754 & 0.02504 & 0.0101 & 0.0067 & 0.1840 & 0.1227 \\
\hline $5 \mathrm{O}$ & -0.188738 & -0.146976 & -0.272371 & 0.04176 & 0.08363 & 0.0112 & 0.0225 & 0.2046 & 0.4098 \\
\hline $6 \mathrm{O}$ & -0.197151 & -0.168658 & -0.278778 & 0.02849 & 0.08162 & 0.0077 & 0.0220 & 0.1396 & 0.4000 \\
\hline $7 \mathrm{~N}$ & 0.235014 & 0.239420 & 0.193255 & 0.00440 & 0.04175 & 0.0012 & 0.0112 & 0.0216 & 0.2046 \\
\hline $8 \mathrm{C}$ & -0.004447 & 0.007625 & -0.015539 & 0.01207 & 0.01109 & 0.0032 & 0.0030 & 0.0592 & 0.0544 \\
\hline $9 \mathrm{C}$ & -0.001680 & 0.024782 & -0.005068 & 0.02646 & 0.00338 & 0.0071 & 0.0009 & 0.1297 & 0.0166 \\
\hline $10 \mathrm{C}$ & 0.002314 & 0.017857 & -0.029614 & 0.01554 & 0.03192 & 0.0042 & 0.0086 & 0.0762 & 0.1565 \\
\hline $11 \mathrm{C}$ & 0.067660 & 0.115375 & 0.035707 & 0.04771 & 0.03195 & 0.0128 & 0.0086 & 0.2338 & 0.1566 \\
\hline $12 \mathrm{C}$ & -0.003587 & 0.019794 & -0.024961 & 0.02338 & 0.02137 & 0.0063 & 0.0058 & 0.1146 & 0.1047 \\
\hline $13 \mathrm{C}$ & -0.019426 & 0.041108 & -0.050936 & 0.06053 & 0.03151 & 0.0163 & 0.0085 & 0.2966 & 0.1544 \\
\hline $14 \mathrm{C}$ & 0.037710 & 0.073211 & -0.007816 & 0.03550 & 0.04552 & 0.0096 & 0.0122 & 0.1740 & 0.2231 \\
\hline $15 \mathrm{C}$ & 0.060119 & 0.117917 & 0.026964 & 0.05779 & 0.03315 & 0.0155 & 0.0089 & 0.2832 & 0.1625 \\
\hline $16 \mathrm{C}$ & 0.032000 & 0.105890 & -0.068122 & 0.07389 & 0.10012 & 0.0199 & 0.0269 & 0.3621 & 0.4906 \\
\hline $17 \mathrm{C}$ & 0.027244 & 0.077415 & -0.035180 & 0.05017 & 0.06242 & 0.0135 & 0.0168 & 0.2459 & 0.3059 \\
\hline $18 \mathrm{C}$ & 0.001778 & 0.029849 & -0.037889 & 0.02807 & 0.03966 & 0.0076 & 0.0107 & 0.1376 & 0.1944 \\
\hline $19 \mathrm{C}$ & 0.252942 & 0.342971 & 0.204487 & 0.09002 & 0.04845 & 0.0242 & 0.0130 & 0.4412 & 0.2374 \\
\hline $20 \mathrm{C}$ & 0.019442 & 0.075432 & -0.037948 & 0.05599 & 0.05739 & 0.0151 & 0.0154 & 0.2744 & 0.2812 \\
\hline $21 \mathrm{C}$ & 0.016208 & 0.092320 & -0.075592 & 0.07611 & 0.0918 & 0.0205 & 0.0247 & 0.3730 & 0.4499 \\
\hline $22 \mathrm{C}$ & 0.014773 & 0.073505 & -0.047009 & 0.05873 & 0.06178 & 0.0158 & 0.0166 & 0.2878 & 0.3028 \\
\hline $23 \mathrm{C}$ & 0.209756 & 0.221156 & 0.196862 & 0.0114 & 0.01289 & 0.0031 & 0.0035 & 0.0559 & 0.0632 \\
\hline
\end{tabular}




\subsection{Thermodynamic Properties}

Computation of thermodynamic properties of molecules is important for both thermochemistry and chemical equilibrium. Statistical thermodynamics with the two key ideas, Boltzmann distribution and the partition function leads to the derivation of the equations utilized for computing thermochemical data in Gaussian programs. The standard thermodynamic functions: heat capacity $\left(C_{p, m}^{o}\right)$, entropy $\left(S_{m}^{o}\right)$ and enthalpy $\left(H_{m}^{o}\right)$ together with the total energy, zero point energy, rotational constants, dipole moment were obtained directly from the output of DFT calculation employing 6-311G $(\mathrm{d}, \mathrm{p})$ basis set and listed in Tables 5a and $\mathrm{b}$.

As observed from the table, the values of $C_{p, m}^{o}, S_{m}^{o}$ and $H_{m}^{o}$ increase with the increase of temperature from $100 \mathrm{~K}$ to $900 \mathrm{~K}$ which is attributed to the enhancement of molecular vibration while the temperature increases. The correlation between temperature and these thermodynamic properties are given in Fig. 3.

Table 5(a): Theoretically calculated thermodynamic properties at different temperatures using 6-311G $(d, p)$ basis set.

\begin{tabular}{lcrc}
\hline $\begin{array}{l}\text { Temperature } \\
(\mathrm{K})\end{array}$ & $\begin{array}{l}\text { Enthalpy } \\
(\mathrm{kJ} / \mathrm{mol})\end{array}$ & $\begin{array}{c}\text { Specific heat } \\
(\mathrm{J} / \mathrm{mol}-\mathrm{K})\end{array}$ & $\begin{array}{l}\text { Entropy } \\
(\mathrm{J} / \mathrm{mol}-\mathrm{K})\end{array}$ \\
\hline 100 & 600.0808 & 109.4366 & 349.5692 \\
200 & 615.3002 & 195.5655 & 457.4258 \\
300 & 639.3226 & 284.6956 & 556.9808 \\
400 & 671.9977 & 366.7323 & 652.7906 \\
500 & 712.2009 & 434.9499 & 744.0818 \\
600 & 758.5195 & 489.2314 & 829.8888 \\
700 & 809.6702 & 532.1265 & 909.9358 \\
800 & 864.6581 & 566.3607 & 984.4193 \\
900 & 922.7266 & 594.0700 & 1053.757 \\
\hline
\end{tabular}

The correlation equations are as follows:

$H_{m}^{o}=583.65002+0.10323 \mathrm{~T}+3.07745 \times 10^{-4} \mathrm{~T}^{2} \quad\left(\mathrm{R}^{2}=0.99952\right)$

$C_{p, m}^{o}=-2.98254+1.12581 \mathrm{~T}-5.14425 \times 10^{-4} \mathrm{~T}^{2} \quad\left(\mathrm{R}^{2}=0.99957\right)$

$S_{m}^{o}=238.13449+1.14381-2.63687 \times 10^{-4} \mathrm{~T}^{2} \quad\left(\mathrm{R}^{2}=0.99999\right)$

These thermodynamic relations would provide useful information for the study of thermodynamic energies and estimate directions of chemical reactions according to the second law of thermodynamics in thermochemical field. Further, these equations could be utilized in predicting the Gibbs free energy, which would help in the judgment of spontaneity of the reactions. [22].

\subsection{Nonlinear Optical properties (NLO)}

Nonlinear optics (NLO) deals with the interactions of applied magnetic fields in various materials to generate new magnetic field altered in phase, frequency, amplitude or other physical properties [23]. Some organic substances with $\pi$ electronic system exhibit the largest known nonlinear coefficients and show promise for thin fabrication, allowing the enormous function and cost integrated electronic circuitry. 


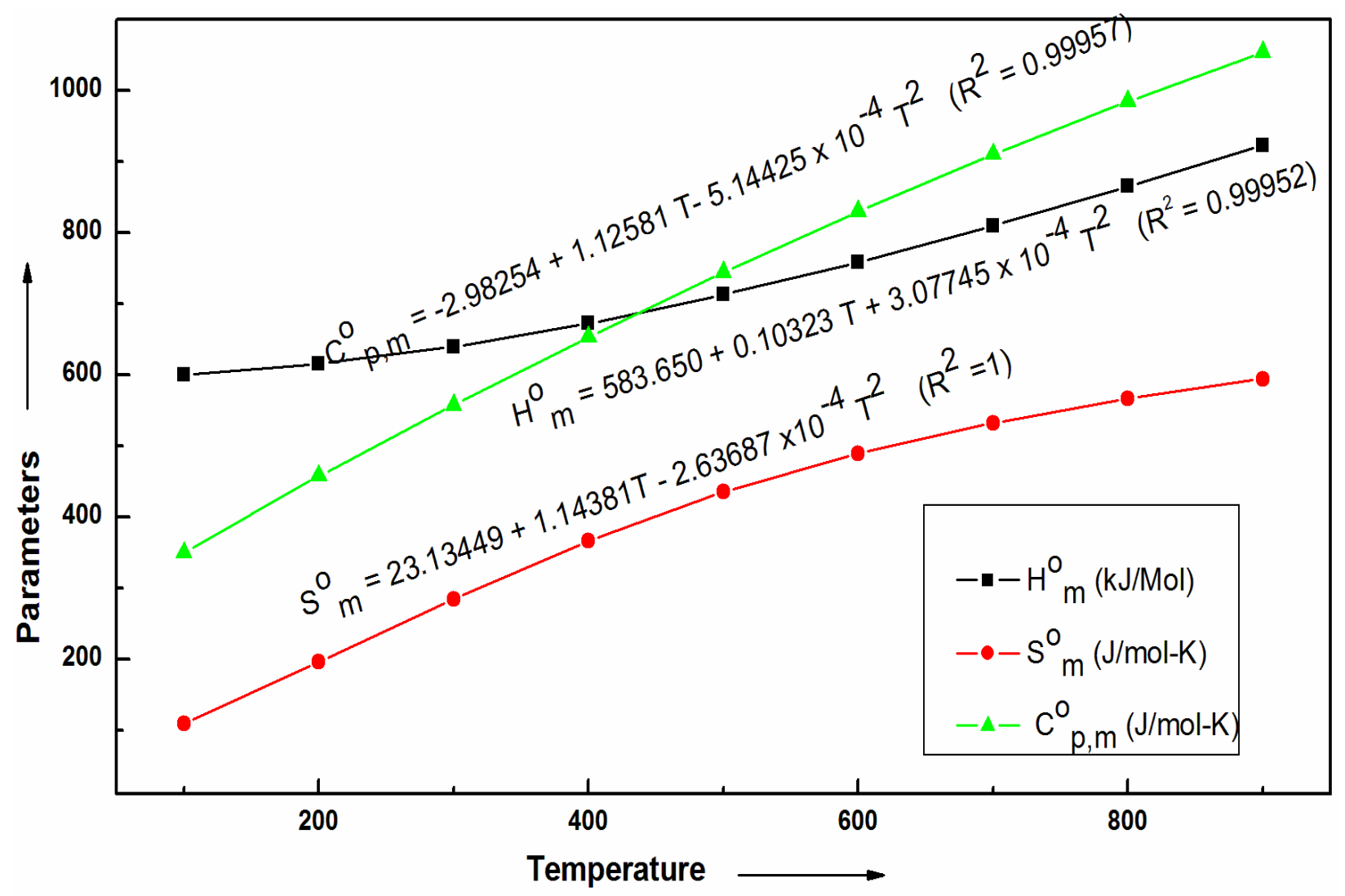

Fig. 3: Correlation between the thermodynamic parameters with the temperature.

Table 5(b): Theoretically calculated thermodynamic properties at room temperature using 6-311G (d,p) basis set.

\begin{tabular}{lll}
\hline Thermodynamic properties & DFT (B3LYP) & HF \\
\hline Total energy $(\mathrm{eV})$ & -30513.38103 & -30336.08362 \\
Zero-point energy $(\mathrm{kJ} / \mathrm{mol})$ & 142.05075 & 151.82499 \\
Rotational constants $(\mathrm{GHz})$ & 0.33647 & 0.33647 \\
& 0.27097 & 0.27097 \\
& 0.15671 & 0.15671 \\
Dipole moment (D) & 6.2937 & 6.8561 \\
Entropy $(\mathrm{J} / \mathrm{mol}-\mathrm{K})$ & 555.17088 & 498.49426 \\
Enthalpy $(\mathrm{kJ} / \mathrm{mol})$ & 638.80014 & 673.31022 \\
Specific heat $(\mathrm{J} / \mathrm{mol}-\mathrm{K})$ & 283.07796 & 256.55586 \\
\hline
\end{tabular}

First hyperpolarizability is a third rank tensor that can be described by a $3 \times 3 \times 3$ matrix. The 27 components of the 3D-matrix can be reduced to 10 components due to the Kleinmann symmetry [21]. It can be given in the lower tetrahedral format. It is obvious that the lower part of the $3 \times 3 \times 3$ matrix is a tetrahedral. The components of $\beta_{0}$ are defined as the coefficients in the Taylor series expansion of the 
energy in the external electric field. When the external electric field is weak and homogeneous this expansion becomes:

$E=E^{0}-\mu_{i} F_{i}-\frac{1}{2} \alpha_{i j} F_{i} F_{j}-\frac{1}{6} \beta_{i j k} F_{i} F_{j} F_{k} \quad \cdots .$.

where $E^{0}$ is the energy of the unperturbed molecules, $F_{i}$ is the field at the origin and $\mu_{i}, \alpha_{i j}, \beta_{i j k}$ are the components of dipole moment, polarizability, and first hyperpolarizability respectively. The total dipole moment $\left(\mu_{0}\right)$, the mean polarizability $\left(\left|\alpha_{0}\right|\right)$, the anisotropy of the polarizability $(\Delta \alpha)$ and the total first hyperpolarizability $\left(\beta_{0}\right)$ using $\mathrm{x}, \mathrm{y}, \mathrm{z}$ components are defined as [24]:

$\mu=\left(\mu_{x}^{2}+\mu_{y}^{2}+\mu_{z}^{2}\right)^{1 / 2}$

$\left|\alpha_{0}\right|=\frac{1}{3}\left(\alpha_{x x}+\alpha_{y y}+\alpha_{z z}\right)$

$\Delta \alpha=2^{-1 / 2}\left[\left(\alpha_{x x}-\alpha_{y y}\right)^{2}+\left(\alpha_{y y}-\alpha_{z z}\right)^{2}+\left(\alpha_{z z}-\alpha_{x x}\right)^{2}+6 \alpha_{x x}^{2}\right]^{1 / 2}$

$\beta_{0}=\left(\beta_{x}^{2}+\beta_{y}^{2}+\beta_{z}^{2}\right)^{1 / 2}$

Where

$\beta_{x}=\beta_{x x x}+\beta_{x y y}+\beta_{x z z}$

$\beta_{y}=\beta_{y y y}+\beta_{x x y}+\beta_{y z z}$

$\beta_{z}=\beta_{z z z}+\beta_{x x z}+\beta_{y y z}$

Since the $\mathrm{x}, \mathrm{y}, \mathrm{z}$ components of $\left|\alpha_{0}\right|, \Delta \alpha$ and $\beta_{0}$ of Gaussian 09 output are reported in a atomic mass unit (a.u.), the calculated values have been converted into electrostatic unit (esu) (for $\left|\alpha_{0}\right|$ : 1 a.u. $=0.1482 \times$ $10^{-24} \mathrm{esu}$; for $\beta_{0}: 1$ a.u. $=0.086393 \times 10^{-31} \mathrm{esu}$ ) and listed in the Table 6 . The high value of $\beta_{0}$, one of the key factors in an NLO system, supports that the investigated molecule will show good NLO response.

Table 6: Dipolemoment ( $\mu$ Debye), polarizability $\left(\alpha \times 10^{-24} \mathrm{esu}\right)$ and first order hyperpolarizability $\left(\beta_{0} \times 10^{-31} \mathrm{esu}\right)$.

\begin{tabular}{|c|c|c|c|c|c|c|c|c|}
\hline \multicolumn{3}{|c|}{ Dipole moment } & \multicolumn{3}{|c|}{ Polarizability } & \multicolumn{3}{|c|}{ Hyperpolarizability } \\
\hline & DFT & $\mathrm{HF}$ & & DFT & $\mathrm{HF}$ & & DFT & $\mathrm{HF}$ \\
\hline$\mu_{x}$ & -5.2839 & -5.2243 & $\alpha_{x x}$ & -119.1408 & -118.3740 & $\beta_{x x x}$ & 27.3548 & 31.7449 \\
\hline$\mu_{y}$ & 4.0465 & 3.7945 & $\alpha_{y y}$ & -121.7131 & -122.2665 & $\beta_{y y y}$ & 53.8593 & 47.8559 \\
\hline$\mu_{z}$ & 0.1350 & 0.2183 & $\alpha_{z z}$ & -136.8908 & -138.6496 & $\beta_{z z z}$ & 5.8486 & 6.4994 \\
\hline \multirow{8}{*}{$\mu_{0}$} & 6.6567 & 6.4607 & $\alpha_{x y}$ & 10.6612 & 12.0501 & $\beta_{x y y}$ & -71.5489 & -71.1348 \\
\hline & & & $\alpha_{x z}$ & -2.7854 & -2.4720 & $\beta_{x x y}$ & 37.2794 & 38.8391 \\
\hline & & & $\alpha_{y z}$ & 0.7627 & 0.7135 & $\beta_{x x z}$ & -17.6840 & -16.7678 \\
\hline & & & $\left|\alpha_{0}\right|$ & -125.9149 & -126.4300 & $\beta_{x z z}$ & 7.6975 & 8.5779 \\
\hline & & & $\Delta \alpha$ & 207.6443 & 206.4903 & $\beta_{y z z}$ & 16.6563 & 18.0840 \\
\hline & & & & 30.7314 & 30.5606 & $\beta_{y y z}$ & 8.8145 & 9.7722 \\
\hline & & & & & & $\beta_{x y z}$ & -9.5344 & -10.3423 \\
\hline & & & & & & $\beta_{0}$ & 9.8355 & 9.4355 \\
\hline
\end{tabular}

\section{Conclusion}

Computational study proves that NBO analysis and NLO properties of the investigated molecule are successfully predicted by the B3LYP/6-311G $(\mathrm{d}, \mathrm{p})$ method. The $\pi \rightarrow \pi^{*}$ interactions are responsible for 
the conjugation of respective $\pi$-bonds within aromatic rings, rings and $\mathrm{C}=\mathrm{O}, \mathrm{NO}_{2}$ groups, which stabilized the molecule with maximum energy $\sim 21.06,17.24$ and $16.48 \mathrm{kcal} / \mathrm{mol}$, respectively. The electron donation related to the resonance interaction in the molecule is mainly confined between the rings and the lone pair groups leading to the maximum energy $168.74 \mathrm{kcal} / \mathrm{mol}$. The calculated high value of electrofilicity index $(\omega)$ is in agreement that the molecule behaves as a global electrophile. The compound exhibits strong effective ICT due to the movement of the $\pi$-electron cloud from donor to acceptor and shows second-order nonlinearity. The value of first order hyperpolarisability $\left(\beta_{0}\right)$ shows that the title molecule can be used as an attractive material for NLO applications.

\section{Acknowledgements}

We acknowledge to Prof. Poonam Tandon, Macromolecular research laboratory, University of Lucknow, India for providing facility of the Gaussian 09 calculations. Also, thanks are to CNPq-TWAS fellowship program for financial support to pursue Post-Doc study in Universidate Federal do Ceara, Fortaleza, Brazil.

\section{References}

[1] A.A. Pozdzik, I.J. Salmon, F.D. Debelle, C. Decaestecker, C, Van den Branden, J.L. Vanherweghem, D. Verbeelen, M.M. Deschodt-Lankman, J.L. Nortier, Kidney International 73 (2008) 595-607. http://dx.doi.org/10.1038/sj.ki.5002714

[2] W. Tang and G. Eisenbrand, Chinese Drugs of Plant Origin-chemistry, Pharmacology and Use in Traditional and Modern Medicine, Springer-Verlag, Berlin, Germany, (1992) pp.145.

[3] B.D. Joshi, A. Srivastava, V. Gupta, P. Tandon and S. Jain, Spectrochim. Acta A 116 (2013) 258. http://dx.doi.org/10.1016/j.saa.2013.07.036

[4] R. Mishra, B.D. Joshi, A. Srivastava, P. Tandon and S. Jain, Spectrochim. Acta A. 118 (2014) 470. http://dx.doi.org/10.1016/j.saa.2013.09.015

[5] J.M. Chamers and P.R. Griffiths, (Eds.), Handbook of Vibrational Spectroscopy, John Wiley and Sons, (2002).

[6] R. Mishra, A. Srivastava, A. Sharma, P. Tandon, C. Baraldiand M.C. Gamberini, Spectrochim. Acta A $101(2013) 335$. http://dx.doi.org/10.1016/j.saa.2012.09.092

[7] P. Hohenberg and W. Kohn, Phys. Rev. 136B (1964) 864. http://dx.doi.org/10.1103/PhysRev.136.B864

[8] J.B. Khadka and B.D. Joshi, BIBECHANA 12 (2015) 40. http://dx.doi.org/10.3126/bibechana.v12i0.11702

[9] www.ncbi.nlm.nih.gov Structure search data base.

[10] M.J. Frisch, G.W. Trucks, H.B. Schlegel, G.E. Scuseria, M.A. Robb, J.R. Cheeseman, G. Scalmani, V. Barone, B. Mennucci, G.A. Petersson, H. Nakatsuji, M. Caricato, X. Li, H.P. Hratchian, A.F. Izmaylov, J. Bloino, G. Zheng, J. L. Sonnenberg, M. Hada, M. Ehara, K. Toyota, R. Fukuda, J. Hasegawa, M. Ishida, T. Nakajima, Y. Honda, O. Kitao, H. Nakai, T. Vreven, J. A. Montgomery, Jr., J.E. Peralta, F. Ogliaro, M. Bearpark, J.J. Heyd, E. Brothers, K.N. Kudin, V.N. Staroverov, R. Kobayashi, J. Normand, K. Raghavachari, A. Rendell, J.C. Burant, S. S. Iyengar, J. Tomasi, M. Cossi, N. Rega, J.M. Millam, M. Klene, J.E. Knox, J.B. Cross, V. Bakken, C. Adamo, J. Jaramillo, R. Gomperts, R.E. Stratmann, O. Yazyev, A.J. Austin, R. Cammi, C. Pomelli, J. W. Ochterski, R.L. Martin, K. Morokuma, V.G. Zakrzewski, G.A. Voth, P. Salvador, J.J. Dannenberg, S. Dapprich, A.D. Daniels, O. Farkas, J.B. Foresman, J. V. Ortiz, J. Cioslowski, and D.J. Fox, Gaussian, Inc., Wallingford CT, (2009).

[11] M.E. Casida and D.P. Chong (Eds.), Recent Developments in Density Functional Theory, vol. 1, World Scientific, Singapore, (1995) pp. 155. 
[12] M.E. Casida, K.C. Casida and D.R. SalahubInt. J. Quantum Chem. 70 (1998) 933. http://dx.doi.org/10.1002/(SICI)1097-461X

[13] C. Lee, W. Yang and R.G. Parr, Phys. Rev. 37B (1988)785. http://dx.doi.org/10.1103/PhysRevB.37.785

[14] M.W. Wong, Chem. Phys. Lett., 256 (1996) 391. http://dx.doi.org/10.1016/0009-2614(96)00483-6

[15] A.P. Scott and L. Radom, J. Phys. Chem. 100 (1996) 16502. http://dx.doi.org/10.1021/jp960976r

[16] F. Weinhold and C.R. Landis, Valency and bonding: A Natural Bond Orbital Donor Acceptor Perspective, Cambridge University Press, New York, (2005).

[17] R.G. Parr and W. Yang, Density Functional Theory of Atoms and Molecules, Oxford University Press, New York, (1989).

[18] R.G. Parr and R.G. Pearson, J. Am. Chem. Soc. 105 (1983) 7512. http://dx.doi.org/0002-7863/83/1505-7512\$01.50/0

[19] P. Geerlings, F. De Proft and W. Langenaeker, Chem. Rev. 103 (2003) 1793. http://dx.doi.org/10.1021/cr990029p

[20] R.G. Parr, L. Szentpály and S. Liu, J. Am. Chem., Soc. 121 (1999) 1922. http://dx.doi.org/10.1021/ja983494x

[21] P.K. Chattaraj and S. Giri, J. Phys. Chem. A 111 (2007) 11116. http://dx.doi.org/10.1021/jp0760758

[22] V. Sathyanarayanmoorthi, R. Karunathan and V. Kannappan, J. Chem. 1155 (2013), 1. http://dx.doi.org/10.1155/2013/258519

[23] D.J. Williams, Angew. Chem. Int. Ed. Engl. 23 (1984) 690. http://dx.doi.org/10.1002/anie.198406901

[24] H. Alyar, Z. Kantarci, M. Bahat and E. Kasap, J. Mol. Struct. 834-836 (2007) 516. http://dx.doi.org/10.1016/j.molstruc.2006.11.066 